\title{
Presenting a model for orders of supply chain coordination using linear programming
}

\author{
Mohammad Mirabi \\ Assistant Professor, Department of Industrial Engineering, \\ Meybod University, Meybod, Iran \\ Seyed Hamid Emadi * \\ Ph.D. Student, Department of Industrial Management, Yazd Branch, \\ Islamic Azad University, Yazd, Iran \\ Mohammad hasan Babaeidareh \\ Ph.D. Student, Department of Industrial Management, Yazd Branch, \\ Islamic Azad University, Yazd, Iran \\ *Corresponding Author: Hamid.emadi7@gmail.com
}

\begin{abstract}
Among the critical industry problems, one is the supply chain. Among the points, reflecting this importance is the coordination of chain orders. Ordering and supplying any event through optimization models has the potential to become competitive advantage. The point that we never face lack or shortage of inventory plays a key role in different areas. Thus, the optimal model can be operational taking into account all the objectives. The purpose of this paper is to provide a model for coordination of supply chain orders using linear programming. The data was evaluated according to expert opinion and in the form of mathematical equation and Gams software. The results showed that the coordination of contractor and supplier orders is largely in the sensitivity analysis group on the values of the objective functions. Moreover, the proposed model also showed that the optimization of order management and unit earnings profit based on it has functional and developmental capabilities.
\end{abstract}

Keyword: order coordination, supply chain, linear planning.

\section{Introduction}

Nowadays, performance of supply chain of an organization compared to rivals is a vital competitive tool in different industries (Sadeghian et al., 2010). Given the globalization and the rapidly changing nature of business, the supply chain has become a tool for organizations that want to compete effectively both locally or globally. Overall, decision-making in the supply chain is done in centralized and decentralized ways. In a centralized supply chain, a single decision maker or the main member, with has access to enough supply information in the supply chain and has the power to make decisions, acts on policy-making for the whole members of the chain (Talaeizadeh et al., 2013). Competitive advantage of an organization largely depends on the supply chain of that organization (HeydariGharabolaq et al., 2009). One of the key concepts of the past few decades is the supplychain management philosophy. The most important cause for focus on this is the ever-increasing increase in competitiveness and efforts to survive in organizations. In recent decades, this has led to the management of procurement, production, and distribution processes to take steps towards the organization's competitive objective (Awasthi et al., 2009). In a supply chain, raw materials are supplied by suppliers, and then they are supplied to retailers or end users. Supply chain consists of all sectors directly or indirectly involved in completing customer orders (Chapr\&meindl, 2000). Moreover, the more competitive a market gets, the more important the management of the orders for the customer becomes (PahlavaniQomi and Amiri, 2016). One of the important functions that supply chain manufacturing companies are always concerned with and the decisions related to it have a significant contribution to their competitiveness is supply chain management (Jafarnejad et al., 2015). Today, intense global competition has led to increased customization and faster response to customers. Growing attention to supply chain performance shows the importance of relying on specific supply chain management practices (Mahmudi et al., 2010). Supply chain coordination is a way of convincing the members of the supply chain that general decisions are made to get the optimal profitability of the whole supply chain (Heidari\& Zaabi Ahmadi, 2015). This study tries to use a linear programming to come up with a mathematical model for optimizing and coordinating the order management problem in the supply chain. In doing so, to specify more precisely the problem parameters in decision-making, we tried to propose the structure of a supply chain in similar industries in operations, materials, supplies and orders. The rest of the paper is organized as follows. In the second part review of literature and in the third part problem will be presented. In the fourth part of modeling, in part five the results based on the decision variables, in the sixth section, results 
based on the sensitivity analysis (the aspect of the innovation and coordination of the order in the study) and in section seven, the discussion and conclusions are reported and examined.

\section{Literature review}

Chaharsoughi and Heidari (2010) examined a decentralized supply chain with a buyer and a supplier, in a multiperiod context, where demand and supply are uncertain. The proposed model shows that the simultaneous coordination of the reorder point and the order quantity can reduce the supply chain costs and divide the profits fairly according to bargaining power of each member. Chaharsoughi et al. (2011) presented a coordination model concerning discounts for coordination of the order quantity and reorder point in a two-level supply chain. They understood that the coordination of the reorder point and order quantity could improve the supply chain profit and the level of service to the customer. Arkan and Hejazi (2012) presented a coordination mechanism based on the credit payment period in a two-level supply chain with one buyer and a supplier designed to provide the buyer with a potential for normal distribution with a scheduled delivery time and ordering cost. Heidari (2014) presented a two-level supply chain in three decentralized, non-coordinated, centralized and coordinated modeling ways according to a new mechanism based on "controlling undetermined issues of delivery times" and attention is paid to encourage retailers to coordinate the re-ordering point with respect to the profitability of the entire supply chain, which can be effective in changing its decisions regarding optimal headto-head supply chain decisions.

Studies in this regard are very limited, so the study ahead has a difference in decision making regarding optimization and use of sensitivity analysis of the results and its effects on the coordination of supply chain orders.

\section{Materials and Methods}

Imagine a supply chain. The flow of goods, sources and services constantly exchange between the members of the chain. If the supply chain in question has a contractor and a supplier, each should have a profit or benefit at the end of each exchange. Thus, the issues or factors that can be exchanged and are decisive are so many. Earnings or profits earned may be separate or single. According to preliminary studies, many factors, such as raw materials and parts and supplies and orders can play a role in the formation of the relationship between the contractor and the supplier and generate profits. The research criterion in this study was to earn the unit profit of the supply chain. For having this axis, the topic is required by the experts, the basis of this proposed model of supply chain orders, as well as other factors mentioned in the forthcoming model. Thus, for analysis of optimality and gaining single unit profit, we will coordinate supply chain orders. The overview of the problem is seen in Figure 1.

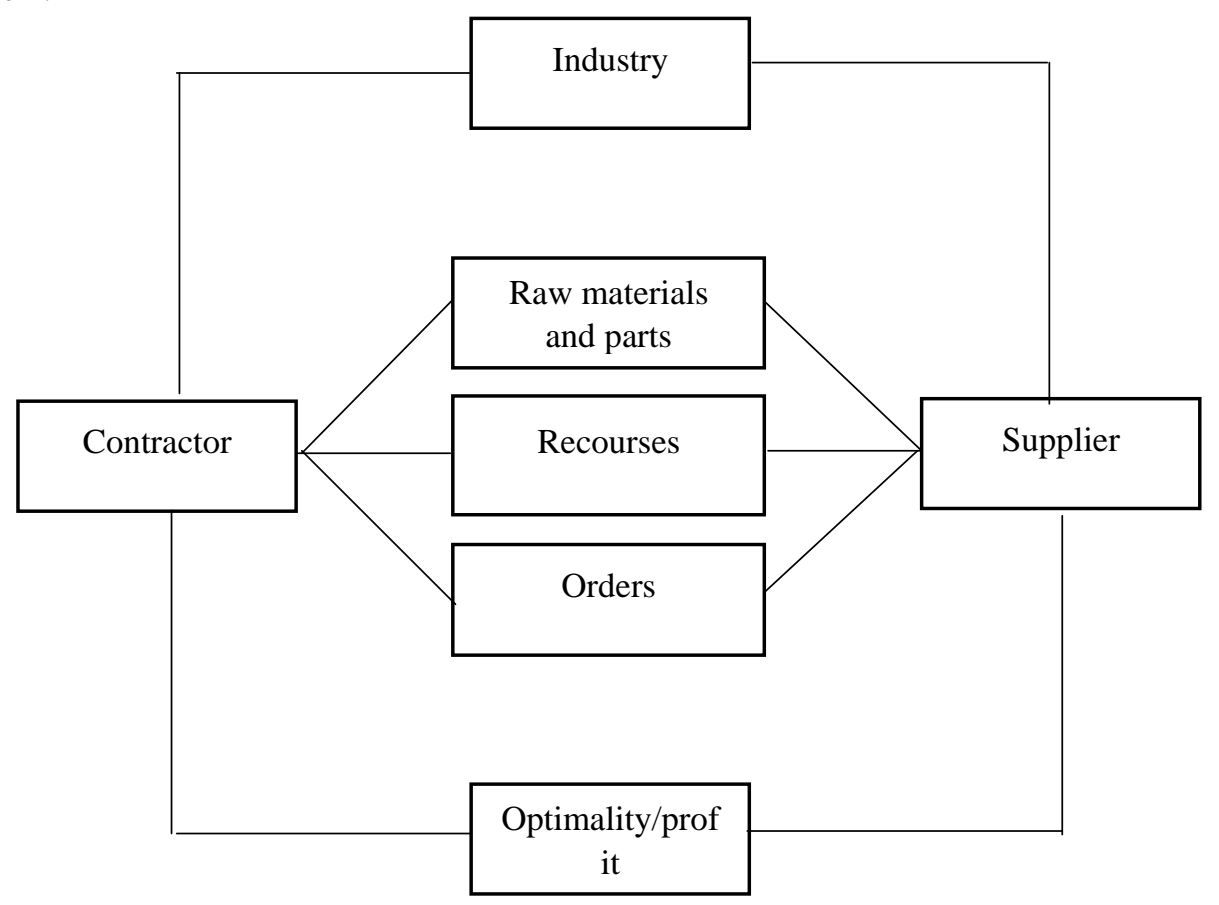

Figure 1: The overview of the problem, and the researcher-made conceptual model (2017) 
To examine the research bases of this study and to collect data, 50 experts (active in various industries) will be interviewed. As the proposed model in this paper is made based on linear programming, it is necessary to introduce the indices, parameters and decision variable to formulate the factors. Table (1), Table (2) and Table (3) show these, respectively.

Table 1: Indices reviewed by experts

\begin{tabular}{|c|c|}
\hline Index & Features \\
\hline S & Contractors \\
\hline L & Suppliers \\
\hline K & Raw materials and parts \\
\hline R & References \\
\hline I & Orders \\
\hline
\end{tabular}

Table 2: The parameters examined by the experts

\begin{tabular}{|c|c|}
\hline Parameters & Features \\
\hline & The proposed price $\mathrm{S}$ for workload of order $\mathrm{i}$, within source $\mathrm{r}$ \\
\hline & $\begin{array}{c}\text { The value of source } \mathrm{r} \text { allocated to order } \mathrm{i} \text { during the period } \mathrm{t} \text { assigned by the } \\
\text { contractor } \mathrm{s}\end{array}$ \\
\hline & $\begin{array}{c}\text { The amount of raw materials and parts of the order i supplied by the supplier } \mathrm{L} \\
\text { during the period } \mathrm{t}\end{array}$ \\
\hline & \begin{tabular}{c} 
The input workload corresponding to the order $\mathrm{i}$ on the source $\mathrm{r}$ at time $\mathrm{t}$ \\
\hline
\end{tabular} \\
\hline & $\begin{array}{c}\text { Maximum available source } \mathrm{r} \text { at normal time in period } \mathrm{t} \\
\text { contractor } \mathrm{s}\end{array}$ \\
\hline & Probability of acceptance of $\mathrm{i}$ order by customer in period $\mathrm{t}$ \\
\hline & The expected defective rate for supplier $\mathrm{L}$ during period $\mathrm{t}$ \\
\hline
\end{tabular}

Table 3: Decision variables studied by experts

\begin{tabular}{|c|c|}
\hline Decision variables & Features \\
\hline & The value of source $\mathrm{r}$ allocated to order $\mathrm{i}$ in the period $\mathrm{t}$ \\
\hline & $\begin{array}{r}\text { If contractor s meets the required workload of order } \mathrm{i} \text { on the } \\
\text { source } \mathrm{r} \text {, otherwise it is zero }\end{array}$ \\
\hline & $\begin{array}{r}\text { If the supplier } \mathrm{L} \text { supplies the raw material and part } \mathrm{k} \text { required } \\
\text { by order } \mathrm{i} \text {, otherwise it is zero }\end{array}$ \\
\hline
\end{tabular}

After showing the research items used, we will use linear programming to coordinate supply chain orders.

\section{Objective function}

The objective function of the problem as linear programming is presented to minimize the average of total production costs, operating costs, parts purchase costs, raw materials and labor costs, and sources, taking into account the required order, period, and inside outsourcing.

\section{Constraints}

The values of $s=1, L=1, K=1,2, R=1,2, I=1,2$, and $T=1,2$, were determined according to expert opinions. These values show that the research problem has been along with a contractor, a supplier, two types of material or parts, two sources, two order periods, and one period. Somehow, the hypothesis is based the fact that periodic studies are related to the financial years 2015 and 2016 in similar state sources in terms of materials, sources, order and time period, and may change over the years. The parameters and their values are summarized in the upcoming tables. Prices are in toman. Capacities are calculated in tons.

Table 4: The value of parameter $\mathrm{P}$

\begin{tabular}{|c|c|c|c|}
\hline Parameter & \multicolumn{3}{|c|}{ Contractor 1} \\
\hline \multirow{3}{*}{$\mathrm{P}$} & \multicolumn{2}{|c|}{ Order 1} & Order 2 \\
\hline & Source 1 & 2000 & 3000 \\
\hline & Source 2 & 2000 & 3000 \\
\hline
\end{tabular}


Table 5: The value of the parameter $\mathrm{p}^{\prime}$

\begin{tabular}{|c|c|c|}
\hline Parameter & \multicolumn{2}{|c|}{ Supplier 1 } \\
\hline \multirow{2}{*}{$\mathrm{p}^{\prime}$} & Raw material 1 & 1200 \\
\cline { 2 - 3 } & Raw material 2 & 1500 \\
\hline
\end{tabular}

Table 6: The value of parameter SE

\begin{tabular}{|c|c|c|c|c|}
\hline Parameter & \multicolumn{4}{|c|}{ Contractor 1 } \\
\hline \multirow{3}{*}{ SE } & \multicolumn{2}{|c|}{ Period 1 } & \multicolumn{2}{c|}{ Period 2 } \\
\cline { 2 - 5 } & \multirow{3}{*}{ Order 1 } & 100 & 100 & Source 1 \\
\cline { 2 - 5 } & & 100 & 100 & Source 2 \\
\cline { 2 - 5 } & \multirow{2}{*}{ Order 2 } & 150 & 150 & Source 1 \\
\cline { 3 - 5 } & & 200 & 200 & Source 2 \\
\hline
\end{tabular}

Table 7: The value of parameter SO

\begin{tabular}{|c|c|c|c|}
\hline Parameter & \multicolumn{3}{|c|}{ Supplier 1 } \\
\hline \multirow{3}{*}{ SO } & \multicolumn{2}{|c|}{ First period } & Second period \\
\cline { 2 - 4 } & Order 1 & 250 & 250 \\
\cline { 2 - 4 } & Order 2 & 300 & 300 \\
\hline
\end{tabular}

Table 8: The value of parameter IW

\begin{tabular}{|c|c|c|c|c|}
\hline Parameter & \multicolumn{2}{|c|}{ First period } & \multicolumn{2}{c|}{ Second period } \\
\hline \multirow{2}{*}{ IW } & Source 1 & 270 & 270 & Source 1 \\
\cline { 2 - 5 } & Source 2 & 270 & 270 & Source 2 \\
\hline
\end{tabular}

Table 9: The value of parameter CR

\begin{tabular}{|c|c|c|c|}
\hline Parameter & \multicolumn{2}{|c|}{ First period } & Second period \\
\hline \multirow{2}{*}{ CR } & Source 1 & 4500 & 4500 \\
\cline { 2 - 4 } & Source 2 & 4500 & 4500 \\
\hline
\end{tabular}

Table 10: The value of parameter CS

\begin{tabular}{|c|c|c|c|}
\hline Parameter & \multicolumn{3}{|c|}{ Contractor } \\
\hline \multirow{3}{*}{ CS } & \multicolumn{2}{|c|}{ First period } & Second period \\
\cline { 2 - 4 } & Source 1 & 4000 & 4000 \\
\cline { 2 - 4 } & Source 2 & 4000 & 4000 \\
\hline
\end{tabular}

Table 11: The value of parameter PR

\begin{tabular}{|c|c|c|c|}
\hline Parameter & \multicolumn{2}{|c|}{ First period } & Second period \\
\hline \multirow{2}{*}{ PR } & Order 1 & 0.9 & 0.9 \\
\cline { 2 - 4 } & Order 2 & 0.9 & 0.9 \\
\hline
\end{tabular}

Table 12: The value of parameter $\mathrm{q}$

\begin{tabular}{|c|c|c|}
\hline Parameter & \multicolumn{2}{|c|}{ Supplier } \\
\hline \multirow{2}{*}{$\mathrm{q}$} & First period & 0.01 \\
\cline { 2 - 3 } & Second period & 0.01 \\
\hline
\end{tabular}

Table 13: The value of parameter CO

\begin{tabular}{|c|c|c|}
\hline Parameter & \multicolumn{2}{|c|}{ Supplier } \\
\hline \multirow{2}{*}{ CO } & First period & 0.01 \\
\cline { 2 - 3 } & Second period & 0.01 \\
\hline
\end{tabular}

The analysis was implemented in Gams software. 


\section{Results based on decision variables}

After entering the information in the Gams software, we could determine the behavior and states of decision making variables based on each index and determine the optimal point. Table (14) contains variables $y, x$, and x` showing $\mathrm{i}$ for 1 and 2, t for 1 and 2, $\mathrm{k}$ for 1 and 2, s for 1 , $\mathrm{L}$ for 1.

Table 14: The results based on the decision variable

\begin{tabular}{|c|c|}
\hline$y_{111}=972$ & $y_{121}=972$ \\
\hline$X_{111}=1$ & $X_{221}=1$ \\
\hline$X^{\prime}{ }_{121}=1$ & $X^{\prime}{ }_{221}=1$ \\
\hline \multicolumn{2}{|c|}{$\mathrm{Z}=8744$} \\
\hline
\end{tabular}

The description of each of the states is as follows:

$\mathrm{y}_{111}=972$ : This means that for the first order, for the first source, the value of $\mathrm{y}$ is 972 tons for the first period.

$\mathrm{y}_{121}=972$ : This means that for the first order, for the second source used, and for the first period, the value of $y$ is 972 tons and equal to the first state.

$\mathrm{X}_{111}=1$ : This means that the first order, for the first source used, and for the single contractor, the problem of $\mathrm{x}$ value is 1 workload.

$\mathrm{X}_{221}=1$ : This means that the second order, for the second source used, and for the single contractor, the problem of $\mathrm{x}$ value is 1 workload.

$\mathrm{X}_{221}^{\prime}=1$ : This means that the first order is used for the second part, and for the single supplier of the problem, the value of $x `$ is 1 of the supply.

$\mathrm{X}_{121}^{\prime}=1$ : This means that the second order for the second piece used for the single supplier of the problem, the value of $x^{`}$ is 1 of the supply.

It is added that the other states of the problem have not been analyzed due to having zero response. It also shows the optimal value of this problem.

\section{Results based on sensitivity analysis on results}

Sensitivity analysis shows what effect the changes in the inputs of a model in a systematic and organized model on the outputs of that model. Table 15 shows the sensitivity analysis on the results of the study. Since the problem is of the coordination of contractor and supplier orders, the decision was made to analyze the sensitivity of the two supply chain members. In doing so, for the validation of two parameters arbitrarily from -50 to $300+$, the effects of these numbers are measured in the function (The selected range of numbers was determined in consultation with experts and without a special basis between numbers $-50,0,100+, 200+, 300+$ ). The result was that if -50 units are lowered from S0 and SE, then the objective function number 8994, if it is constant (the effect of zero interference), S0 and SE are unchanged, and the same as 8744. If +100 units plus S0 and SE are added to the objective function number 7444, if +200 units are added to S0 and SE, then the number of the objective function is 7044, and if +300 units are added to S0 and SE, then the objective function number will be 6650 . This means that as we increase validation, the value of the objective function decreases, and as we lower validation effect, the value of the objective function increases. So we will have:

The following table has summarized: Coordination of orders is largely dependent on sensitivity analysis.

Table 15: Sensitivity analysis on results

\begin{tabular}{|c|c|}
\hline Validation Parameters & Objective function value \\
\hline SO, SE -50 & $\mathrm{Z}=8994$ \\
\hline SO, SE & $\mathrm{Z}=8744$ \\
\hline $\mathrm{SO}, \mathrm{SE}+100$ & $\mathrm{Z}=7444$ \\
\hline $\mathrm{SO}, \mathrm{SE}+200$ & $\mathrm{Z}=7044$ \\
\hline $\mathrm{SO}, \mathrm{SE}+300$ & $\mathrm{Z}=6650$ \\
\hline
\end{tabular}

Conclusion

Companies increasingly compete with each other over the variety of products and service aspects including commitment to the order and delivery time. Quality and costs are important criteria for market competition, so that precision over the order commitment, the speed of delivery as well as the frequency of delivery of the goods can make the order more successful. With parallel advances in technology, manufacturing systems approach a new philosophy, so that they can establish a solid relationship between customers and suppliers to eventually form an integrated supply chain. Moreover, product life cycle is steadily decreasing, which needs order management and considerable flexibility. Furthermore, traditional code order management models do not have a 
specific commitment to end up with existing and future merchandise. Therefore, the key to timing such production systems is to provide a timely commitment to the customer. However, usually commitment to order and comprehensive scheduling criteria are not considered simultaneously, and costing standards of the companies so far have less evaluated this problem that when they can be profitable. The operational capacity models used for order management activities are considered by understanding the process constraints and balancing the flow of materials through the production chain and in meeting the customer's needs. On the contrary, to produce production for real-time order, we need to have a profitability model and a commitment to effective orders to transform the order acceptance and production scheduling into a joint decision-making process, so generate productive activities preventing non-addictive value or minimizing these activities. The activity of the supply chain begins with the customer's order and finishes when customer finishes purchasing the goods and services received. The difference between the money the customer pays with the total costs incurred by the chain to produce and distribute the goods is defined as the profitability and supply chain management involves managing flow between and within each step of the chain to record its overall profitability. Firstly, supply chain management considers any cost-cutting approach playing a role in meeting the customer's needs (from the supplier and facilities to the raw materials and distribution centers, and retail and storehouses. Secondly, supply chain management is increasing efficiency and reducing costs throughout the system. By using the approaches to supply chain management, the total cost of the system, including transport, inventory, transfer, and other costs is reduced. However, it does not emphasize that the cost of transport and inventories will decrease yet that supply chain management will try to improve the whole chain performance and increase the level of customer service by using a systematic approach. Supply chain management and will bring together the efforts of the company, suppliers, manufacturers, traders, customers, who contribute to customer needs. This approach first tries to reduce the cost of the company by optimally planning the production and supply of components and materials and providing timely delivery of the required materials in a timely manner. Finally, production and inventory planning will increase the profitability of the company. Supply chain management leads to closer relationships between the value chain components, so as to provide higher quality products in relevant markets, in a timely manner, and at reasonable prices to customers. The purpose of this approach is developing strong relationships among supply chain of the organization so that they can act in an integrated way, fully integrate with business processes, and maximize customer satisfaction. If no significant value is offered to customers by the supply chain, and the managers conclude that the organization alone cannot provide significant improvements, then they think of employing supply chain management to deliver products and services faster, with better quality and at lower costs.

\section{References}

[1] Arkan, Ali\&Hejati, S.Reza. (2012). Coordinating order in a two echelon supply chain with controllable Lead time and ordering cost using the credit period . Computers\& Industrial Engineer, 62, 56-69.

[2] Chaharsoghi, S. Kamal, Heydari, Jafar\&Nakhaikamalabadi, Isa. (2011). Simultaneous coordination of order quantity and reorder Point in a two- stage supply chain. Computers\& operations Research, 38, 1667-1677.

[3] Chaharsooghi,S. Kamal\&Heydari,j (2010). Supply chain Coordination for the Joint determination of order quantity and reorder Point using credit option . Eurpen Journal of operational Research , 204, 86-95.

[4] Chopra, sunil\&meindl, peter.(2000). Supply chain management strategic planning and operations : Strategy. Planning and operation. New york prentice Han.

[5] HeidariGharabolag, H., Moheb Rabbani, S., ZandHesami, H. (2009). The Effective Effect of E-Commerce on Supply Chain Management. Technology Growth, Volume 6, Issue 21, Page 42-48.

[6] Heidari, J., Zoghabi Ahmadi, P. (2015). Coordination of ordering policies and service levels in the decentralized supply chain, with some uncertainty at delivery times. Journal of Extension of Supply Chain Management, Eighteenth Year, No. 52, pp. 60-66

[7] Heydari. J. (2014). Lead time variation control using reliable shipment equipment: A incentive Scheme for supply chain coordination Transportation Research part E: Logistics and Ttamsportation Review, 63. 44-58.

[8] Jack, C., Terry,P. Harrison, X\& James, He (2011). The impact of stochastic Lead time reduction on inventory cost under order crossover. European Journal of operational Research, 211, 274-281.

[9] Jafarnejad, A., Safari, H., Azar, A., and Ebrahimi, S.A. (2015). Optimal management of supply chain orders using an activity-based costing approach, robust optimization and dynamic simulation. Journal of Operational Research in its Applications, Year 12, Issue 2, pp. 19-36

[10] Mahmoudi, E., NaeimiSedigh, A., Chaharsoughi, S.K., Eskandari, H.R. (2010). Investigating the Influence of Information Flow on Supply Chain Modeling Based on Dynamic System Approach Order. Journal of Modeling in Engineering, Eighth, No. 22, pp. 12-36.

[11] PahlavaniQomi, M., Amiri, M. (2016). Provides a two-level model for pricing and ordering in a three-level supply chain. New research in decision making, Volume 1, Issue 1, Page 27-53

[12] Sadeghian, S.H., Eghbali, M.A., Hajian, A. (2010). Supply Chain Analysis with the Dynamic Approach System Case Study: Manufacturer of Medical Equipment. Seventh International Industrial Engineering Conference, Isfahan, Iran Engineering Society.

[13] Talaeizadeh, A0, Niki, S.T.A \& Wee, Hm (2013). Joint single vendor- single Buyer supply chain problem with stochastic demand and fuzzy lead- time knowledge- based system. 48, 1-9. 